\title{
Acute effects of different doses of malathion on the rat liver
}

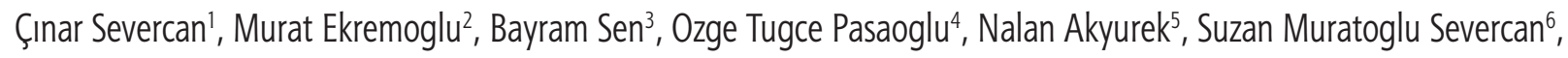 \\ Hatice Pasaoglu ${ }^{3}$
}

'Department of Biochemistry, Faculty of Pharmacy, Zonguldak Bulent Ecevit University, Turkey

${ }^{2}$ Department of Medical Biochemistry, Faculty of Medicine, Altinbas University, Turkey

${ }^{3}$ Department of Medical Biochemistry, Faculty of Medicine, Gazi University, Turkey

${ }^{4}$ Department of Medical Laboratory, College of Health Care Services, Gazi University, Turkey

${ }^{5}$ Department of Pathology, Faculty of Medicine, Gazi University, Turkey

${ }^{6}$ Department of Medical Biochemistry, Institute of Health Science, Gazi University, Turkey

\begin{abstract}
Aim of the study: Our study was designed to evaluate the acute effects of malathion on rat liver tissues.

Material and methods: The animals were divided into 4 groups of 6 animals/each. Group 1 (control group) received corn oil, while groups 2, 3, and 4 were given malathion dissolved in corn oil at a dose of 100, 200 and $400 \mathrm{mg} / \mathrm{kg}$, respectively. 24 hours after malathion administration, animals were sacrificed and liver tissues were collected. The liver tissues were then analysed biochemically and histopathologically.

Results: Butyrylcholinesterase levels in groups 2, 3 and 4 were significantly lower than that of group 1. Total oxidant status and tumour necrosis factor alpha level were significantly increased in group 4 compared to group 1. Catalase activities of groups 3 and 4 were significantly higher than that of group 1. Arylesterase activity was significantly decreased in groups 3 and 4 compared to group 1. In groups 3 and 4, some vacuoles in hepatocytes were revealed and hydropic degeneration was observed in group 4.
\end{abstract}

Conclusions: Acute administrations of malathion results in hepatotoxicity in a dose-dependent manner. Key words: inflammation, oxidative stress, liver, malathion, histopathological examination.

\section{Address for correspondence}

Dr. Çınar Severcan, Department of Biochemistry, Faculty of Pharmacy, Zonguldak Bulent Ecevit University, Turkey, e-mail: cinarsevercan@gmail.com

\section{Introduction}

Organophosphates are highly toxic pesticides with a high chemical mortality ratio. According to a World Health Organization (WHO) report, approximately 3 million organophosphate poisoning cases occur per year, either accidentally or intentionally including suicide attempts. Especially in agricultural countries, organophosphates, mostly preferred pesticides due to their low price and high yield, are one of the common causes of hospital admission [1]. Organophosphates inhibit acetylcholinesterase (AChE) and butyrylcholinesterase (BChE) in the body. BChE is synthesized in the liver and released into the blood [2].
Malathion [O,O-dimethyl-S-(1,2-dicarbethoxyethyl) phosphorodithioate], the most common pesticide among the organophosphates, causes toxicity to the liver, kidneys, testicles and brain of both humans and animals. Malathion is rapidly metabolized in the body to its bioactive analogue malaoxon. It is soluble in lipids and is stored in the liver, causing a significant increase in reactive oxygen species (ROS) [3].

Epidemiological, clinical and experimental evidence indicate the hepatoprotective effects of antioxidants. In addition, some antioxidants inhibit the inflammatory process during hepatosteatosis [4].

Paraoxonase-1 (PON1) is an enzyme synthesized by the liver and has the capacity to hydrolyse aromatic 
carboxylic acid esters and organophosphates in the plasma. PON1 has two main forms, paraoxonase and arylesterase. Both of them are used in clinical and experimental studies [5]. Paraoxonase is an antioxidant enzyme used in the detoxification of lipid peroxidation. Paraoxonase plays an active role in reducing the toxic effects of organophosphate compounds and nerve gases by hydrolyzing them [6]. Arylesterase catalyzes the hydrolysis of 1-phenyl acetate and it is also reported that arylesterase is a protective enzyme against oxidative stress along with paraoxonase [7].

It is reported that organophosphates cause increased levels of inflammatory cytokines such as tumour necrosis factor $\alpha$ (TNF- $\alpha$ ) and interleukin 6 (IL-6), as observed in rat studies [8].

Chronic administration of malathion leads to liver damage, causing enlargement of sinusoids and vacuole formation in hepatocytes, leukocytic infiltrations, dilation and congestion of blood vessels with haemorrhage [9].

We planned to study the effects of acute malathion using various doses in the causation of oxidative stress, inflammation and histopathological changes in rat livers.

\section{Material and methods}

This study was accepted by Gazi University Board of Local Ethics under code number G.Ü. ET. 14.015. All chemicals used in this study were purchased from SIGMA.

Twenty-four female Wistar albino rats with an average weight of $230 \mathrm{~g}$ were used in this study. The animals were randomly assigned to four groups of 6 animals each. Group 1 (control group) was given corn oil; group 2, group 3 and group 4 were given malathion at 100,200 and $400 \mathrm{mg} / \mathrm{kg}$ doses, respectively. These doses of malathion were chosen due to its acute toxic effects at $100 \mathrm{mg} / \mathrm{kg}$, which is known as a toxic dose, the $400 \mathrm{mg} / \mathrm{kg}$ plateau level (70\% inhibition of cholinesterase) and $200 \mathrm{mg} / \mathrm{kg}$, which is considered as an intermediate value [10]. 24 hours later, the animals were sacrificed under ketamine/xylazine anaesthesia and liver tissues were collected by dissecting the liver diagonally and vertically into 4 pieces. Parts of the liver tissues were suspended in neutral buffered formalin for histopathological analysis. The remaining liver tissues were kept at $-80^{\circ} \mathrm{C}$ then taken out and homogenized in $50 \mathrm{mM}$ Tris$\mathrm{HCl}$ buffer at a $1 / 10$ ratio $(500 \mathrm{mg}$ liver tissue $+4500 \mathrm{ml}$ Tris-HCL). Supernatants were centrifuged at $3500 \mathrm{rpm}$ for 1 hour and preserved at $-80^{\circ} \mathrm{C}$ until use. The liver samples were analysed using standard methods to determine the amount of protein in liver tissue [11], BChE activity (Roche Diagnostics brand Cobas E411 model
AutoAnalyzer), malondialdehyde (MDA) level [12], advanced oxidation protein products (AOPP) levels [13], total oxidant status (TOS) level (Rel Assay Diagnostics Kit, catalogue no: RL0024), superoxide dismutase (SOD) activity [14], catalase activity [15], arylesterase activity [16] and TNF-a level (YH Bio search brand; catalogue no: YHB1098Ra).

For histopathological examinations, liver tissues were cut into $4 \mu \mathrm{m}$ thickness and stained with hematoxylin and eosin. Histopathologic examination and photographing of the tissue damage were done with an Olympus brand model Cx30 binocular light microscope.

SPSS version 20 was used to evaluate the data. The Kruskal-Wallis test was used to determine whether there was a significance differences among the 4 groups. A $p$ value $\leq 0.05$ was accepted as statistically significant and the Mann-Whitney $U$ test with Bonferroni correction was used to determine statistical differences between two groups. Since there were 6 pairwise comparisons for 4 groups, the $p$ value (0.05) was divided by 6 according to Bonferroni correction $(0.05 / 6=$ 0.0083 ). Differences between two groups were considered significant when $p \leq 0.008$. Correlation analysis was performed using Spearman's correlation test.

\section{Results}

A significant decrease in liver BChE activities was observed in groups 2, 3 and 4 compared to group 1 ( $p \leq 0.008)$. There were no significant differences in liver SOD activities or MDA levels among the groups. There was a significant increase in liver AOPP levels of groups 3 and 4 compared to group 2 ( $p \leq 0.008$ ). Liver TOS levels were significantly raised in group 4 compared to groups 1 and $2(p \leq 0.008)$. Moreover, a significant increase in TOS level was also seen in group 3 compared to group $2(p \leq 0.008)$. Liver catalase activity showed a significant increase in groups 3 and 4 compared to group $1(p \leq 0.008)$. A significant increase in liver arylesterase enzyme activities was observed in groups 3 and 4 in comparison with group 1 ( $p \leq 0.008)$. Liver TNF- $a$ level was significantly increased in group 4 compared to group $1(p \leq 0.008)$. The results of biochemical analyses mentioned above are presented in Table 1.

The results of correlation analysis revealed a strong and significant positive correlation between liver AOPP and TOS, TOS and catalase, AOPP and catalase, BChE and arylesterase as well as TNF- $\alpha$ and catalase $(p \leq 0.01)$. On the other hand, negative correlations were observed between liver TOS and arylesterase activity $(p \leq 0.01)$ liver arylesterase and catalase $(p \leq 0.05)$, as shown in Table 2. 
Table 1. Results and significant differences of liver parameters

\begin{tabular}{lcccc}
\hline Parameters & Group $1(n=6)$ & Group $2(n=6)$ & Group 3 $(n=6)$ & Group 4 $(n=6)$ \\
\cline { 2 - 5 } & Mean \pm SD & Mean \pm SD & Mean \pm SD & Mean \pm SD \\
\hline BChE $(\mathrm{U} / \mathrm{mg}$ prot.) & $382^{*} 10^{-3} \pm 111^{*} 10^{-3}$ & $179^{*} 10^{-3} \pm 33^{*} 10^{-3 \mathrm{a}}$ & $219^{*} 10^{-3} \pm 52^{*} 10^{-3 b}$ & $189^{*} 10^{-3} \pm 38^{*} 10^{-3 \mathrm{c}}$ \\
\hline MDA (nmol/g tissue) & $252.5 \pm 56.55$ & $303.33 \pm 139.34$ & $314.17 \pm 92.33$ & $255 \pm 80.99$ \\
\hline AOPP (mmol/mg prot.) & $85.73 \pm 25.55$ & $75.53 \pm 16.37$ & $120.98 \pm 40.72^{\mathrm{d}}$ & $133.27 \pm 42.51^{\mathrm{e}}$ \\
\hline TOS $(\mu \mathrm{mol} / \mathrm{l})$ & $84.80 \pm 8.98$ & $79.13 \pm 10.52$ & $97.61 \pm 7.78^{\mathrm{d}}$ & $117.97 \pm 17.20^{\mathrm{ce}}$ \\
\hline Catalase $(\mathrm{U} / \mathrm{mg}$ prot.) & $1.65 \pm 0.29$ & $2.08 \pm 0.47$ & $2.59 \pm 0.58^{\mathrm{b}}$ & $2.67 \pm 0.44^{\mathrm{c}}$ \\
\hline SOD $(\mathrm{U} / \mathrm{mg}$ prot.) & $0.96 \pm 0.29$ & $0.92 \pm 0.21$ & $1.18 \pm 0.28$ & $1.33 \pm 0.35$ \\
\hline Arylesterase $(\mathrm{U} / \mathrm{mg}$ prot.) & $60.40 \pm 12.26$ & $47.41 \pm 10.18$ & $40.26 \pm 5.14^{\mathrm{b}}$ & $36.88 \pm 8.25^{\mathrm{c}}$ \\
\hline TNF- $\alpha$ (ng/l) & $277.76 \pm 60.80$ & $333.69 \pm 32.16$ & $353.78 \pm 50.62$ & $406.19 \pm 85.74$ \\
\hline
\end{tabular}

$n$ - number of animals, significance $p \leqslant 0.008$ (difference between group 1 and group 2), ${ }^{b}$ significance $p \leqslant 0.008$ (difference between group 1 and group 3), ssignificance $p \leqslant 0.008$ (difference between group 1 and group 4), dsignificance $p \leqslant 0.008$ (difference between group 2 and group 3), esignificance $p \leqslant 0.008$; difference between group 2 and group 4), fsignificance $p \leqslant 0.008$ (difference between group 3 and group 4)

BChE - butyrylcholinesterase, MDA - malondialdehyde, AOPP - advanced oxidation protein products, TOS - total oxidant status, SOD - superoxide dismutase, TNF-a - tumor necrosis factor $a$

Table 2. Correlation analysis among liver parameters

\begin{tabular}{|c|c|c|c|c|c|c|c|}
\hline & & BChE & AOPP & TOS & Catalase & Arylesterase & TNF- $\alpha$ \\
\hline \multirow[t]{3}{*}{ BChE } & $r$ & 1 & 0.21 & -0.2 & -0.15 & $0.66 * *$ & -0.25 \\
\hline & $p$ & & 0.32 & 0.36 & 0.49 & 0.00 & 0.23 \\
\hline & $n$ & 24 & 24 & 24 & 24 & 24 & 24 \\
\hline \multirow[t]{3}{*}{ AOPP } & $r$ & 0.21 & 1 & $0.52^{* *}$ & $0.76^{* *}$ & -0.24 & 0.32 \\
\hline & $p$ & 0.32 & & 0.01 & 0 & 0.25 & 0.13 \\
\hline & $n$ & 24 & 24 & 24 & 24 & 24 & 24 \\
\hline \multirow[t]{3}{*}{ TOS } & $r$ & -0.2 & $0.52 * *$ & 1 & $0.57^{* *}$ & $-0.58^{* *}$ & 0.31 \\
\hline & $p$ & 0.36 & 0.01 & & 0.01 & 0.01 & 0.14 \\
\hline & $n$ & 24 & 24 & 24 & 24 & 24 & 24 \\
\hline \multirow[t]{3}{*}{ Catalase } & $r$ & -0.15 & $0.76^{* *}$ & $0.57^{* *}$ & 1 & $-0.43^{*}$ & $0.53^{* *}$ \\
\hline & $p$ & 0.49 & 0.00 & 0.00 & & 0.04 & 0.01 \\
\hline & $n$ & 24 & 24 & 24 & 24 & 24 & 24 \\
\hline \multirow[t]{3}{*}{ Arylesterase } & $r$ & $0.66 * *$ & -0.24 & -0.58 ** & $-0.43^{*}$ & 1 & -0.28 \\
\hline & $p$ & 0.000 & 0.25 & 0.00 & 0.04 & & 0.19 \\
\hline & $n$ & 24 & 24 & 24 & 24 & 24 & 24 \\
\hline \multirow[t]{3}{*}{ TNF- $\alpha$} & $r$ & -0.25 & 0.32 & 0.31 & $0.53^{* *}$ & -0.28 & 1 \\
\hline & $p$ & 0.23 & 0.13 & 0.14 & 0.01 & 0.19 & \\
\hline & $n$ & 24 & 24 & 24 & 24 & 24 & 24 \\
\hline
\end{tabular}

*significant correlation at the 0.05 level, ** significant correlation at the 0.01 level, $r$ - correlation coefficient, $p$ - significance, $n$ - number of individuals $B C h E$ - butyrylcholinesterase, AOPP - advanced oxidation protein products, TOS - total oxidant status, TNF-a - tumor necrosis factor a

The results of histopathological observations showed that there was no liver tissue damage in group 1 or 2 (Figs. 1 and 2) while some vacuoles in hepatocytes were seen in groups 3 and 4 , and hydropic degeneration was detected in group 4 (Figs. 3 and 4).

\section{Discussion}

Malathion, a commonly used organophosphate, exerts its effects by inhibiting the serum enzymes AChE and BChE [17]. In this study, acute toxic effects were 


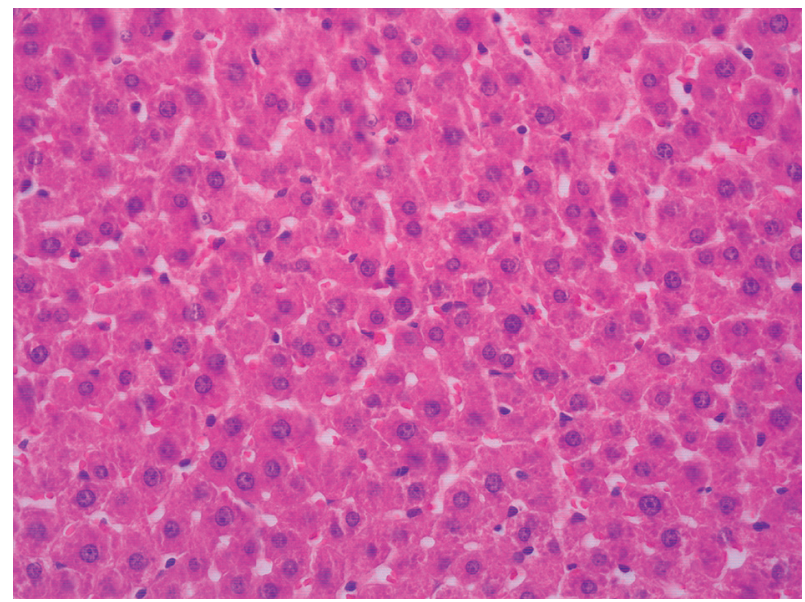

Fig. 1. Histopathologic observation of group 1. There was no degeneration

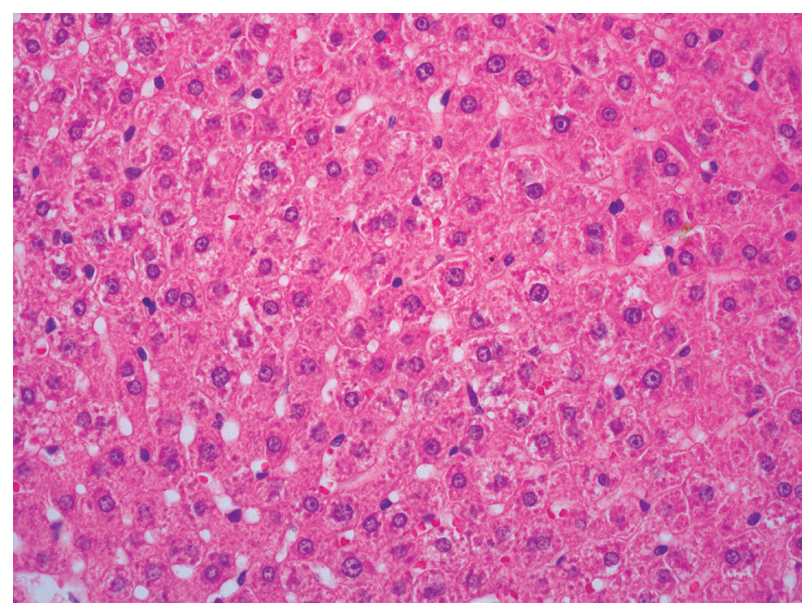

Fig. 3. Histopathologic observation of group 3. Some vacuoles in hepatocytes were seen

selected as $100 \mathrm{mg} / \mathrm{kg}$ as an acute effect, $400 \mathrm{mg} / \mathrm{kg}$ as the plateau level (70\% AChE inhibition) and $200 \mathrm{mg} / \mathrm{kg}$ as a medial dose [10]. Studies showed that sub-chronic and chronic administration of malathion inhibits liver BChE activity $[18,19]$.

In this study, a significant decrease in liver BChE activities was observed in groups 2,3 and 4 in comparison with group 1 ( $p \leq 0.008)$. The results of this study conducted by acute administration of malathion are in line with previous studies performed using chronic administration of malathion.

Various studies have indicated that chronic and sub-chronic applications of malathion in rats cause increased liver lipid peroxidation [18, 20-22]. Al-Othman et al. reported that acute administration of malathion at a dose of $27 \mathrm{mg} / \mathrm{kg}$ resulted in a significant increase in liver MDA level [23]. In contrast, Possamai et al. reported that there was no significant liver lipid peroxidation observed in rats treated with acute dos-

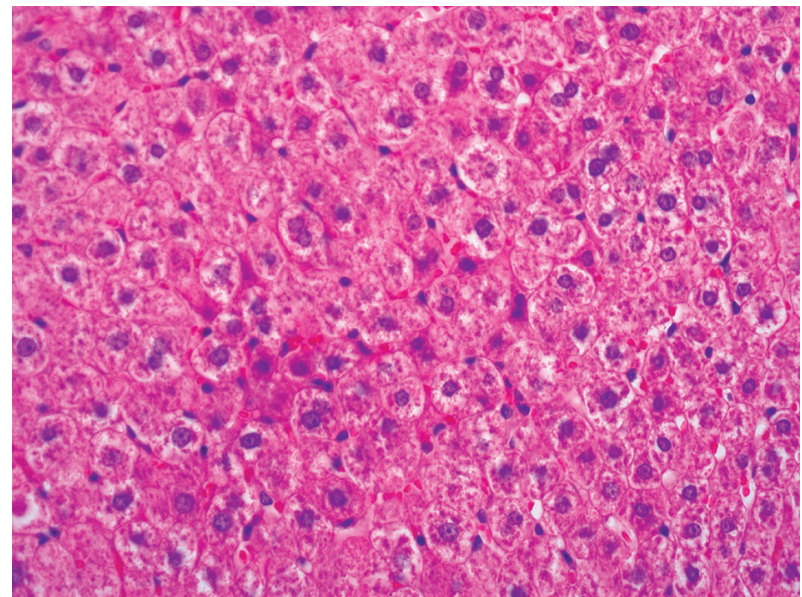

Fig. 2. Histopathologic observation of group 2. There was no degeneration

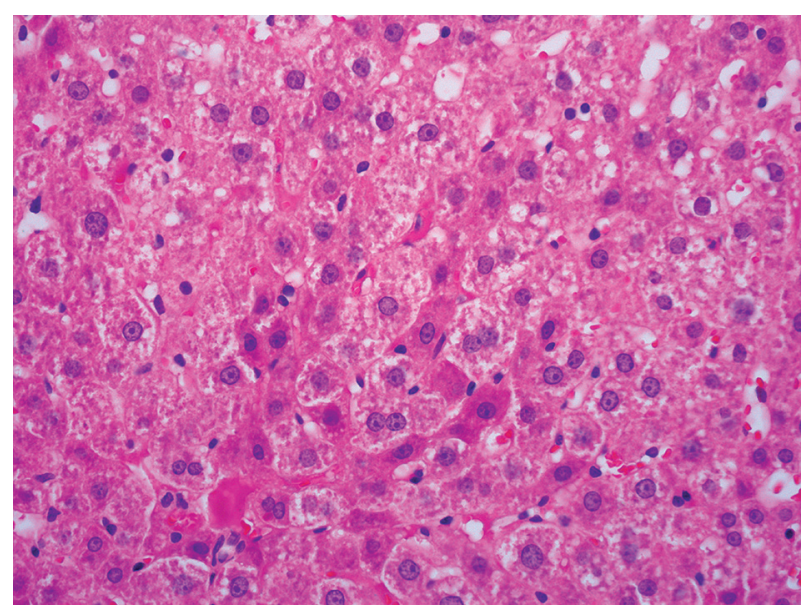

Fig. 4. Histopathologic observation of group 4. Vacuolar and hydropic degeneration in hepatocytes was seen

es of malathion at 100 and $150 \mathrm{mg} / \mathrm{kg}$. Possamai et al. also reported that there was an increase in protein carbonyls indicating an increase in protein oxidation at $50 \mathrm{mg} / \mathrm{kg}$ acute dosage but there were no such effect at 100 and $150 \mathrm{mg} / \mathrm{kg}$ doses [22]. In this study, there were no statistically significant differences in liver MDA level among the groups. Thus, the results of this study are in line with those of Possamai et al. Liver AOPP levels of groups 3 and 4 were significantly higher than in group $2(p \leq 0.008)$ but were not significantly higher than in group 1.

It was also found that TOS levels were significantly increased in group 4 compared to groups 1 and 2 . Liver TOS levels in group 3 were also significantly higher than in group $2(p \leq 0.008)$. Results of the Spearman correlation analysis revealed a strong and significant correlation between liver AOPP and TOS levels $(p \leq 0.01)$. This indicates that liver advanced protein and total oxidation levels increase in a complementary 
way. Since there was no significant change in MDA levels, it is believed that protein oxidation is the main contributor to total oxidation observed in this study. The results of some previous studies showed that chronic applications of malathion resulted in a decrease in SOD activity and catalase in rat liver [20,21]. Similarly, acute applications of malathion at a dose of 25 and $50 \mathrm{mg} / \mathrm{kg}$ also decreased rat liver SOD activity [22]. A study performed by Al-Othman et al. also gave similar results [23]. On the other hand, a study by Sharma et al. showed that acute application of dimethoate, an organophosphate, increased liver catalase and SOD activity [24].

In this study, an increase in SOD activity was observed in groups 3 and 4 but this increase was not statistically significant. There was a significant increase in catalase activity in groups 3 and 4 compared to group 1 $(p \leq 0.008)$.

Sharma et al. reported that acute administration of organophosphates resulted in an increase in liver cytochrome P450 activity. Cytochrome P450 enzymes catalyze oxidation of oxygen molecules in organophosphate substrates and trigger the production of ROS [24]. Łukaszewicz-Hussain and Moniuszko-Jakoniuk reported that acute application of chlorfenvinphos, an organophosphate, contributed to an increase of ROS production by increasing hepatic $\mathrm{O}^{2-}$ and reducing the mitochondrial aconitase level [25]. It is also reported that 24 hours after chlorfenvinphos administration, liver SOD and catalase levels were increased in line with the increase in superoxide anion [26]. Łukaszewicz-Hussain and Moniuszko-Jakoniuk also reported that 48 hours after chlorfenvinphos application catalase activity was decreased. The increase in catalase and GSH-Px activity following organophosphate application was found to be sufficient to lower the toxic effects of $\mathrm{H}_{2} \mathrm{O}_{2}$. However, 48 hours after organophosphate administration, catalase activity was decreased to a very low level as GSH-Px activity is sufficient to decrease the level of $\mathrm{H}_{2} \mathrm{O}_{2}$ [27]. As a result, a conclusion can be made that 24 hours after organophosphate application, catalase, SOD and GSH-Px increase in reaction to the increasing liver ROS. It is thought that a continuous increase in ROS following sub-chronic administration of organophosphates may decrease activities of these antioxidant enzymes.

Based on the results of the correlation analysis, a strongly significant positive correlation was observed between liver TOS and catalase activity as well as AOPP and catalase activity $(p \leq 0.01)$. This study revealed that an increase in ROS (increasing TOS and AOPP) induced catalase activity within $24 \mathrm{~h}$ of organophosphate administration.
The results of this study are in line with previous studies reported by Sharma et al. [24], Łukaszewicz-Hussain [26], Łukaszewicz-Hussain and Moniuszko-Jakoniuk [25], and Łukaszewicz-Hussain and Moniuszko-Jakoniuk [27], but our results contradict studies of Possamai et al. [22] and Al-Othman et al. [23]. This may be due to a low dose of malathion administered acutely during liver antioxidant activity studies. In this study, acute administration of malathion at a dose of $100 \mathrm{mg} / \mathrm{kg}$ did not show a significant difference in oxidative stress and antioxidant enzymes. Significant increases in liver oxidative stress and catalase activities were observed after acute administration of malathion at a dose of 200 and $400 \mathrm{mg} / \mathrm{kg}$.

Łukaszewicz-Hussain demonstrated that rats' paraoxonase activity was significantly decreased with an increase in serum lipid peroxidation after sub-chronic application of chlorpyrifos [28]. In this study, liver arylesterase activities in groups 3 and 4 were significantly decreased in comparison with that of group 1 $(p \leq 0.008)$. Based on the results of correlation analysis, there was a strong significant negative correlation between TOS level and liver arylesterase activity $(p \leq 0.01)$. The results of this study revealed that acute administration of malathion at a dose of 200 and $400 \mathrm{mg} / \mathrm{kg}$ resulted in a significant decrease in arylesterase activity with an in increase TOS. This demonstrated for the first time the relationship between liver arylesterase activity and TOS following acute administration of malathion in rats.

A study by Akgür et al. identified a significant correlation between paraoxonase activity and $\mathrm{BChE}$ in the sera of humans exposed to acute organophosphate poisoning [29]. Akgür et al. also reported that chronic administration of organophosphate did not reveal a significant correlation between paraoxonase activity and AChE [6]. It is reported that paraoxonase plays a more effective role in acute organophosphates poisoning than chronic organophosphate poisoning [29].

The results of this study also showed a strong positive correlation between liver arylesterase activity and $\mathrm{BChE}(p \leq 0.01)$. It is found that with increasing dose of malathion (acute administration) rats' liver $\mathrm{BChE}$ and arylesterase activities decrease simultaneously.

Experimental studies showed that chronic administration of organophosphates resulted in an increase in serum TNF- $\alpha$ levels and inflammation in rats' brain, Langerhans islets, and macrophages [6]. Gordon and Rowsey reported that acute administration of chlorpyrifos gave rise to an increased serum TNF- $\alpha$ level [30]. Mostafalou et al. [19] and Ince et al. [21] reported that chronic administration of malathion increases liver TNF- $\alpha$ level. 
In this study, there was a significant increase in the liver TNF- $\alpha$ level of group 4 compared to that of group 1 $(p \leq 0.08)$. Thus, this result indicated that acute administration of malathion a dose of $400 \mathrm{mg} / \mathrm{kg}$ caused a significant increase in liver TNF- $a$ level.

A study by Selmi et al. showed that chronic administration of malathion caused enlargement of sinusoids, mononuclear cell infiltration, dilatation, haemorrhage and necrosis of rats' liver tissues [31]. Similar results were observed in studies by Al-Attar [9].

In this study, the results of histological examinations showed that acute administration of malathion at a dose of $200 \mathrm{mg} / \mathrm{kg}$ was seen some vacuoles, in addition to observing vacuolar and hydropic degeneration at a dose of $400 \mathrm{mg} / \mathrm{kg}$ in the liver tissues. However, acute administration of malathion at a dose of $100 \mathrm{mg} / \mathrm{kg}$ did not cause any significant histological changes.

\section{Conclusions}

We believe the results obtained from this study could provide comprehensive data regarding the effects of acute administration of malathion on the liver oxidant and antioxidant system, inflammatory indicators and histological parameters. We believe that this study will encourage new ideas about the acute dose of malathion which causes liver damage and has malign impacts on human health and the environment to be determined and prevented and also to make regulations for its dose for agricultural products in domestic and foreign markets.

\section{Acknowledgments}

This study was conducted at Gazi University Medical Biochemistry Research Laboratories, Ankara, Turkey and was supported by Gazi University Scientific Research Projects under project code 01/2015-01. None of the authors has a commercial interest, financial interest, and/or other relationship with manufacturers of pharmaceuticals, laboratory supplies, and/or medical devices or with commercial providers of medically related services.

\section{Disclosure}

The authors report no conflict of interest.

\section{References}

1. Vanova N, Pejchal J, Herman D, et al. Oxidative stress in organophosphate poisoning: role of standard antidotal therapy. J Appl Toxicol 2018; 38: 1058-1070.

2. Picco EJ, Fernández HR, David DC, et al. Use of cholinesterase activity in monitoring chlorpyrifos exposure of steer cattle after topical administration. J Environ Sci Health B 2008; 43: 405409.

3. Buratti FM, D'Aniello A, Volpe MT, et al. Malathion bioactivation in the human liver: the contribution of different cytochrome P450 isoforms. Drug Metab Dispos 2005; 33: 295-302.

4. Lasram MM, Annabi AB, Rezg R, et al. Effect of short-time malathion administration on glucose homeostasis in Wistar rat. Pestic Biochem Physiol 2008; 92: 114-119.

5. Gupta N, Gill KD, Singh S. Paraoxonase 1 (PON1) activity, polymorphisms and coronary artery disease. In: A. Squeri (ed.). Coronary artery disease - new insights and novel approaches. InTech China, Shanghai 2012; 115-136.

6. Akgür SA, Oztürk P, Sözmen EY, et al. Paraoxonase and acetylcholinesterase activities in humans exposed to organophosphorous compounds. J Toxicol Environ Health A 1999; 58: 469-474.

7. Gur M, Yildiz A, Demirbag R, et al. Paraoxonase and arylesterase activities in patients with cardiac syndrome $\mathrm{X}$, and their relationship with oxidative stress markers. Coron Artery 2007; 18: 89-95.

8. Hariri AT, Moallem SA, Mahmoudi M, et al. Sub-acute effects of diazinon on biochemical indices and specific biomarkersin rats: protective effects of crocin and safranal. Food Chem Toxicol 2010; 48: 2803-2808.

9. Al-Attar AM. Physiological and histopathological investigations on the effects of alpha-lipoic acid in rats exposed to malathion. J Biomed Biotechnol 2010; 2010: 203503.

10. Karami-Mohajeri S, Hadian MR, Fouladdel S, et al. Mechanisms of muscular electrophysiological and mitochondrial dysfunction following exposure to malathion, an organophosphorus pesticide. Hum Exp Toxicol 2014; 33: 251-263.

11. Lowry OH, Rosebrough NJ, Farr AL, et al. Protein measurements with the folin phenol reagent. J Biol Chem 1951; 193 : 265-275.

12. Ohkawa H, Ohishi N, Yagi K. Assay for lipid peroxides in animal tissues by thiobarbituric acid reaction. Anal Biochem 1979; 95: 351-358.

13. Witko-Sarsat V, Friedlander M, Capeillère-Blandin C, et al. Advanced oxidation protein products as a novel marker of oxidative stres in uremia. Kidney Int 1996; 49: 1304-1313.

14. Sun Y, Oberley LW, Li Y. A simple method for clinical assay of superoxide dismutase. Clin Chem 1988; 34: 497-500.

15. Aebi H. Catalase in vitro. Methods Enzymol 1976; 105: 121-126.

16. Beltowski J, Jamroz-Wiśniewska A, Borkowska E, et al. Differential effect of antioxidant treatment on plasma and tissue paraoxonase activity in hyperleptinemic rats. Pharmacol Res 2005; 51: 523-532.

17. Bartling A, Worek F, Szinicz L, et al. Enzyme-kinetic investigation of different sarin analogues reacting with human acetylcholinesterase and butyrylcholinesterase. Toxicology 2007; 233: 166-172.

18. Akhgari M, Abdollahi M, Kebryaeezadeh A, et al. Biochemical evidence for free radicalinduced lipid peroxidation as a mechanism for subchronic toxicity of malathion in blood and liver of rats. Hum Exp Toxicol 2003; 22: 205-211.

19. Mostafalou S, Eghbal MA, Nili-Ahmadabadi A, et al. Biochemical evidence on the potential role of organophosphates in hepatic glucose metabolism toward insulin resistance through inflammatory signaling and free radical pathways. Toxicol Ind Health 2012; 28: 840-851.

20. Akbel E, Arslan-Acaroz D, Demirek HH, et al. The subchronic exposure to malathion, an organophosphate pesticide, causes 
lipid peroxidation, oxidative stress, and tissue damage in rats: the protective role of resveratrol. Toxicol Res 2018; 7: 503-512.

21. Ince S, Arslan-Acaroz D, Demirel HH, et al. Taurine alleviates malathion induced lipid peroxidation, oxidative stress, and proinflammatory cytokine gene expressions in rats. Biomed Pharmacother 2017; 96: 263-268.

22. Possamai FP, Fortunato JJ, Feier G, et al. Oxidative stress after acute and sub-chronic malathion intoxication in Wistar rats. Environ Toxicol Pharmacol 2007; 23: 198-204.

23. Al-Othman AM, Khaled S, Al-Numair KS, et al. Protection of a-tocopherol and selenium against acute effects of malathion on liver and kidney of rats. Afr J Pharm Pharmacol 2011; 5: 1263 1271.

24. Sharma Y, Bashir S, Irshad M, et al. Effects of acute dimethoate administration on antioxidant status of liver and brain of experimental rats. Toxicology 2005; 206: 49-57.

25. Lukaszewicz-Hussain A, Moniuszko-Jakoniuk J. Activity of mitochondrial aconitase and liver concentration of hydrogen peroxide in acute intoxication with chlorfenvinphos in rat. Pol J Environ Stud 2003; 12: 177-180.

26. Łukaszewicz-Hussain A. Organophosphate insecticide chlorfenvinphos affects superoxide dismutase, catalase and malondialdehyde in rat liver. Pol J Environ Stud 2001; 10: 279-282.

27. Łukaszewicz-Hussain A, Moniuszko-Jakoniuk J. Liver catalase, glutathione peroxidase and reductase activity, reduced glutathione and hydrogen peroxide levels in acute intoxication with chlorfenvinphos, an organophosphate insecticide. Pol J Environ Stud 2004; 13: 303-309.

28. Łukaszewicz-Hussain A. Paraoxonase activity and lipid peroxides concentration in serum of rats subchronically intoxicated with chlorpyrifos - organophosphate insecticide. Med Pr 2012; 63: 559-564.

29. Akgür SA, Oztürk P, Solak I, et al. Human serum paraoxonase (PON1) activity in acute organophosphorous insecticide poisoning. Forensic Sci Int 2003; 133: 136-140.

30. Gordon C, Rowsey PJ. Are circulating cytokines interleukin-6 and tumor necrosis factor a involved in chlorpyrifos-induced fever? Toxicology 1999; 134: 9-17.

31. Selmi S, Rtibi K, Grami D, et al. Malathion, an organophosphate insecticide, provokes metabolic, histopathologic and molecular disorders in liver and kidney in prepubertal male mice. Toxicol Rep 2018; 5: 189-195. 